\title{
Laudation for Dr. Ir. Peter Bode
}

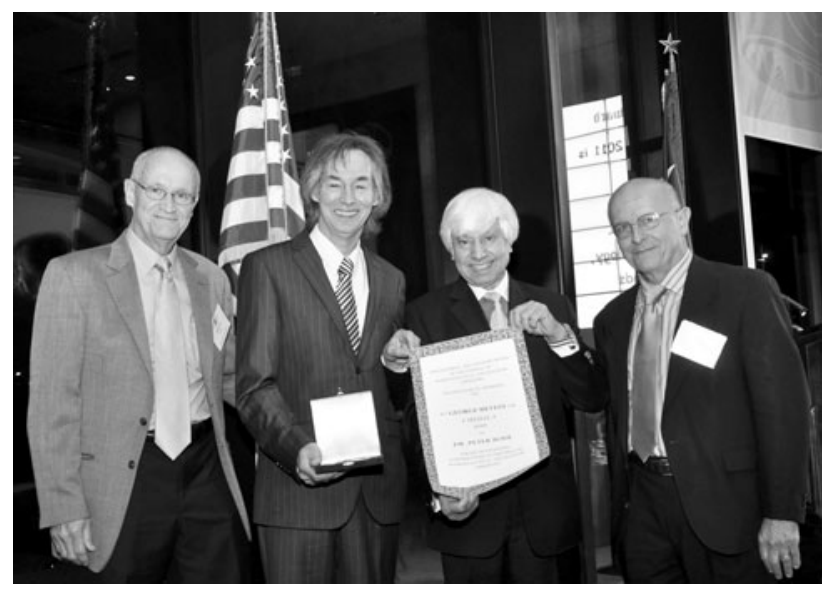

Dr. Peter Bode was born in Vlissingen, The Netherlands. He obtained his graduate degree in Chemical Engineering and Technology at the Delft University of Technology during 1965-1971 and wrote a thesis on the use of short half-life radionuclides in NAA. He received his doctorate degree from the same University in 1996 on a thesis entitled "Instrumental and organizational aspects of a neutron activation analysis laboratory" under the supervision of Professors Marcel de Bruin and Jeroen J. M. de Goeij. Dr. Bode is presently an Associate Professor in Nuclear Science and Engineering at the Delft University of Technology.

Dr. Bode worked on the development of instrumental neutron activation analysis (INAA) at the Department of Radiochemistry with Prof. Jan Houtman (1970-1987). He became the primary scientist responsible for the determination of short half-life radionuclides. Since 1981 he has also directed his attention to perturbed angular correlation spectrometry as a tool for non-invasive, non-destructive speciation analysis. During 1987-2002 Dr. Bode was the head of the Physical and Mathematical Methods in Radioanalysis.

For many years he was the head of an NAA laboratory in Delft, performing thousands of analyses. He recognized very early that formal quality management practices were necessary to assure the customers that his analyses embodied the best laboratory practices and are metrologically traceable to the International System of Units. In 1989 he initiated the development of a quality management system which resulted in 1993 in the world's first NAA laboratory with an internationally recognized accreditation. Since then Dr. Bode has been tirelessly sharing his experience with colleagues all over the world. His passion for quality and collaboration with a few other colleagues has convinced the Consultative Committee for Amount of Substance-Metrology in Chemistry (CCQM) in 2007 to designate NAA as a primary ratio method of measurement.

Dr. Bode has vigorously promoted the use of INAA to analyze large samples, and designed and installed the world's first large sample INAA facility during 1989-92 where he can irradiate and count samples up to several kilograms in size. This approach has two practical advantages, namely analysis of inhomogeneous samples and use of low neutron flux.

Dr. Bode was an expert for the International Atomic Energy Agency in more than two dozen countries on six continents. In many cases, these scientific visits have led to publications with scientists from the host countries. His bibliography lists contributions in seven languages. Since 1987 Dr. Bode gave lectures on NAA and quality assurance, quality management, and laboratory accreditation, held many training courses and workshops, and contributed to Technical Documents. He hosted and trained in Delft many IAEA fellows and other scientific visitors. He drafted a collaborative work plan that resulted in 2009 in the 
designation of the Reactor Institute Delft as an IAEA Collaborating Center for Neutron Activation Based Methodologies of Research Reactors.

Dr. Bode is currently involved in projects on radionuclide production based on recoil chemistry, design of new dedicated irradiation facilities and radiotracer methodology for the behaviour and fate of nanomaterials used in nuclear medicine. He participates in the major upgrade of the Delft research reactor and neutron beam facilities and on the 'Holland Particle Therapy Centre', a particle cancer therapy clinic considered to be built on the premises of the Reactor Institute Delft. He is co-applicant of a patent on the production of no-carrier added ${ }^{99} \mathrm{Mo}$.

Dr. Bode has been repeatedly consulted by various Brazilian metrology organizations for his expertise in QA/ QC and metrology in chemical measurements. Since 2003, he has been active as a visiting professor at the Universidade de São Paulo, Centro de Energia Nuclear na Agricultura (CENA) in Piracicaba in the post-graduate program, providing courses on metrology and quality assurance.

Dr. Bode published about 150 scientific papers in internationally peer reviewed journals and has about 180 additional contributions to journals, books, (internet) encyclopaedia, conference proceedings, and as scientific reports. Dr. Bode has contributed to the educational curriculum of the Delft University of Technology, founding in 2009 an MSc specialization Nuclear Science and Engineering, the first of its kind in the history of the Delft University. At home in Delft, he has been mentor to a large number of MSc and PhD level students. He also gave about 115 presentations, mostly invited, at international scientific conferences and seminars.

Dr. Bode is a co-recipient of the Brazilian Prêmio de Excelência em Metrologia of the Sociedade Brasileira de Metrologia in 2002. He also received a Gold Jubilee Medal from the Delft University of Technology in 2010 for 40 years of continuous service.

It is a pleasure to honor Dr. Peter Bode with the Hevesy Medal Award 2011.

Prepared by

Professor Dr. A. Chatt

Chair, Hevesy Medal Award Selection Panel 2011

President, International Committee on Activation Analysis 